\title{
Tuberculous perforation of the small bowel
}

\author{
N.O. Aston and A.M. de Costa
}

Dudley Road Hospital, Birmingham, UK.

\begin{abstract}
Summary: Small bowel perforation occurs in up to 2 percent of patients with abdominal tuberculous. Patients present with an acute abdomen. Resection of the diseased segment and 18 months treatment with anti-tuberculosis drugs is recommended.
\end{abstract}

\section{Introduction}

The overall incidence of free intestinal perforation in patients with abdominal tuberculosis is close to that of $2 \%$ recorded in one of the largest series from India (Mukerjee \& Singal, 1979). In Britain this complication is rare. Only one case has been reported in series published over the last two decades (Mandal \& Schofield, 1976). We report 3 cases diagnosed at laparotomy. All patients presented acutely with abdominal pain and vomiting of less than $24 \mathrm{~h}$ duration. None gave a history of previous tuberculosis.

\section{Case reports}

\section{Case 1}

A 30 year old Asian woman had signs of generalized peritonitis. Free peritoneal gas was seen on a plain abdominal radiograph. At operation a perforated ileal stricture and multiple peritoneal tubercles were found. The involved segment was resected. She developed a wound haematoma that required evacuation under anaesthesia on the sixth post operative day. No further complication occurred.

\section{Case 2}

A sixteen year old Asian girl had signs of acute appendicitis. A localized perforation of the distal ileum was found; the appendix was normal. Small bowel resection and appendicectomy were performed. She made an uneventful recovery.

N.O. Aston, F.R.C.S.; A. M. de Costa, F.R.C.S., F.R.C.S.I. Correspondence, and present address: N.O. Aston, Kent and Canterbury Hospital, Canterbury, Kent CT1 3NG

Accepted: 15 March 1984

\section{Case 3}

A 77 year old white man was found to have a rigid abdomen and absent bowel sounds. The perforated ileal stricture found at laparotomy was resected and the appendix removed. He died of bronchopneumonia on the tenth post-operative day.

Histological examination showed caseation, the presence of acid-fast bacilli or both in all cases. The two survivors were treated with anti-tuberculous drugs. Both remain well after 2 years follow-up.

\section{Discussion}

Patients with abdominal tuberculosis are usually young Asians. Only a minority have a history of previous pulmonary tuberculosis or an abnormal chest radiograph. Over $50 \%$ of patients have chronic abdominal symptoms which are often mild and nonspecific (Bhansali et al., 1968). These include pain, weight loss, nausea, diarrhoea and constipation.

Those who perforate present with acute abdominal pain and signs of generalized or localized peritonitis. Occasionally perforation leads to abscess formation (Mandal \& Schofield, 1976). Although any part of the small bowel or colon may perforate, the most frequent site is the distal ileum. A diagnosis of acute appendicitis will often be made if the signs are localized to the right iliac fossa. Radiographic evidence of free peritoneal gas is found in only $25 \%$ of cases (Bhansali et al., 1968).

A single perforation is present in $90 \%$ of cases. Perforation occurs within or proximal to an area of stricture formation. An element of obstruction is frequently present and fluid levels seen on the plain abdominal radiograph add to the difficulties of diagnosis (Bhansali et al., 1968). In few reported cases has

(C) The Fellowship of Postgraduate Medicine, 1985 
the diagnosis of tuberculous perforation been made prior to laparotomy.

Perforation may occur during treatment of pulmonary tuberculosis (Sweetman \& Wise, 1959). Iatrogenic perforation may be caused by Cope needle peritoneal biopsy for suspected tuberculosis in patients with ascites (Sherman et al., 1980).

The most effective treatment is resection of the diseased segment with an end to end anastomosis. Because tuberculous strictures are short, unlike those of Crohn's disease, an alternative and quicker treatment for those who are critically ill is oval excision of the perforated area with a transverse anastomosis reinforced by an omental patch (Pujari, 1979). The results of oversewing alone are poor (Bhansali et al., 1968). Even when a bypass is added, fistula formation frequently occurs (Ahmad, 1962). Although strictures are multiple in over $50 \%$ of cases strictureplasty or resection of those remaining is rarely necessary (Muk-

\section{References}

ABRAMS, J.S. \& HOLDEN, W.D. (1964). Tuberculosis of the gastrointestinal tract. Archives of Surgery, 89, 282.

AHMAD, M. (1962). Acute tuberculous perforation of the small intestine. Journal of the Indian Medical Association, 38, 317.

BHANSALI, S.K., DESAI, A.N. \& DHABOOWALA, C.B. (1968).

Tuberculous perforation of the small intestine. Journal of the Association of Physicians of India, 16, 351.

FINDLAY, J.M. (1982). Medical management of gastrointestinal tuberculosis. Journal of the Royal Society of Medicine, 75, 583.

MANDAL, B.K. \& SCHOFIELD, P.F. (1976). Abdominal tuberculosis in Britain. Practitioner, 216, 683. erjee \& Singal, 1979). Removing the appendix is a safe procedure even if microscopic evidence of tuberculosis is present (Abrams \& Holden, 1964). The overall $\stackrel{\circ}{\circ}$ mortality of perforation is $30 \%$ but may be considerably higher in the elderly and in those who have already become cachectic from the underlying disease (Man- $\stackrel{9}{?}$ dal \& Schofield, 1976).

The excised specimen should be sent for histological examination and a segment of diseased tissue or lymph $\frac{\bar{\omega}}{7}$ node cultured for mycobacteria. This is particularly $\stackrel{\mathbb{D}}{\Omega}$ important in the elderly, in whom peritoneal tubercles may be diagnosed as disseminated malignant disease. The standard post-operative treatment is triple therapy with rifampicin, isoniazid and ethambutol. $\vec{\omega}$ An 18 month course is probably necessary. Corticosteroids are frequently added empirically to this re- $\overrightarrow{0}$ gimen for 2 months to reduce the degree of cicatrisa- 3 tion that may occur with healing (Findlay, 1982).

MUKERJEE, P. \& SINGAL, A.K. (1979). Intestinal tuberculosis: 500 operated cases. Proceedings of the Association of Surgeons of East Africa, 2, 70.

PUJARI, B.D. (1979). Modified surgical procedures in intes- $\frac{\widehat{O}}{工}$ tinal tuberculosis. British Journal of Surgery, 66, 180.

SHERMAN, S., ROHWEDDER, J.J., RAVIKRISHNAN, K.P. WEG, J.G. (1980). Tuberculous enteritis and peritonitis Archives of Internal Medicine, 140, 506.

SWEETMAN, W.R. \& WISE, R.A. (1959). Acute perforated tuberculous enteritis: surgical treatment. Annals of Surgery, 149, 143. 